\title{
LA TEORIA HEGELIANA DE LA SOCIEDAD CIVIL: LA PRIMERA CRÍTICA CONTEMPORÁNEA A LA CONCEPCIÓN LIBERAL DE LA SOCIEDAD
}

\author{
Enrique Olivas \\ ICEJC - Universidad Complutense de Madrid
}

\begin{abstract}
Resumen: Los "'Principios de la Filosofía del Derecho", publicada en 1821, es una obra sobre el derecho y el Estado. Se trata un texto contemporáneo sobre el Estado y, específicamente, sobre el constitucionalismo social que iba a desplegarse en Europa un siglo después. Con una información inmensa, nuestro autor despliega el "desarrollo del espíritu" a través de los momentos del Derecho Abstracto, la Moralidad y, finalmente, de la Eticidad. Dentro de la sección dedicada a ésta, analiza Hegel el concepto de sociedad civil,-bürgerliche Gesellschaft-,desbrozando sus elementos constitutivos. Esta noción de sociedad civil, se había popularizado por la economía política clásica, ya desde el ensayo de Adam Ferguson "An Essay of the History of Civil Society", Entre los parágrafos 182 y 256, Hegel estudia una forma social que considera escindida del Estado, que separa la existencia social de los individuos, en sí misma y en sus relaciones mutuas, de todo vínculo sustancial, personal y ético y pone como único principio social general el principio egoísta, según el cual, cada uno es fin para sí mismo y todo lo demás es nada. Con esta abstracción "real" de un ser enajenado, la satisfacción en todas las direcciones de sus necesidades, del arbitrio contingente, conduce hacia el espectáculo de la miseria y el libertinaje con la corrupción física y ética que es común a ambas(par.185). Sin embargo, la característica esencial de este análisis es mostrar la necesidad lógica y política de la intervención del Estado, en tanto que esfera de la Eticidad, en la organización de sus dimensiones diferenciadas. Es opinión reiterada de Hegel, que sólo en el Estado la sociedad se organiza según la razón. A no olvidar: "únicamente con el conocimiento de que la idea de libertad es sólo verdadera como Estado, se asegura que el espíritu objetivo, el contenido del derecho, no sea nuevamente reducido a su concepto subjetivo" (par.57).
\end{abstract}

Palabras clave: Derecho, Estado, constitucionalismo social, derecho abstracto, moralidad, eticidad, sociedad civil, principio egoísta, arbitrio contingente, razón, idea de libertad

\section{The Hegel Theory of the Civil Society: The first contemporary critic of the liberal conception of the society, from the reading of the "Principles of the Philosophy of the Right"}

Abstract: The "Principles of the Philosophy of the Right", published in 1821, is a work about Right and the State. It is a contemporary text about the State and, specifically, about the social constitutionalism that was arising in Europe a year later. With a lot of documentation, our author exposes the development of the spirit through the moments of the Abstract Right, the Morality, and, finally, of the Ethics. In the section dedicated to latter, Hegel analyzes the concept of civil society -bürgerliche Gessellschaft-, clearing its constituent elements. This notion of civil society, was already popular in the classic politic economy, starting from the essay by Adam Ferguson "An Essay of the History of Civil Society". Between the paragraphs 182 and 256, Hegel studies a social form that he considers divided from the State, that separates the social existence of the individuals in themselves and in their mutual relations, of all their substantial, personal and ethic link and put as only general social principle, the selfish principle, that says, each person is the end for himself and everything else is nothing. With this "true" abstraction of an alienated person, the satisfaction in every directions of his necessities, of the contingent will, drive to the show of the misery and the lechery with the physic and ethic corruption that is common to both (par. 185). However, the essential characteristic of this analysis is to show the 
logical and politics necessity of the intervention of the State, understood as field of the Ethics, in the organization of its dimensions differentiated. It is reiterated opinion by Hegel, that only in the State the society is organized according to the reason. No forget: "only with the knowledge that the idea of the liberty can only be true as State, is assured that the objective spirit, the content of the right, not be newly reduced to it subjective concept" (par. 57).

Kaywords: Law, State, social constitutionalism, abstract right, morality, ethics, civil society, selfish principle,"true" abstraction, contingent will, reason, idea of the liberty

"Pertenece a la cultura, al pensar como conciencia del individuo en la forma de la universalidad, que yo sea aprehendido como persona universal, en lo cual todos somos idénticos: El hombre vale porque es hombre y no porque sea judío, católico, protestante, alemán o italiano. La conciencia de este valor del pensamiento es de una infinita importancia."1

La sociedad civil ${ }^{2}$, como cualesquiera otros fenómenos, debe ser situada en el correspondiente proceso histórico en el cual se constituye. En el relevante "Prefacio" de los "Grundlinien", Hegel asigna al filósofo de la sociedad y del Estado no ya propósitos de evaluación y reforma de la finitud histórica, sino, con precisión, la tarea "realista" de penetrar la naturaleza esencial de aquella sociedad, mediante la referencia de los hechos históricos a sus conceptos. Es interesante observar que ahí se halla latente la idea de libertad, que para nuestro autor, constituye la centralidad del derecho contemporáneo ${ }^{4}$.

La teoría hegeliana de la sociedad civil,-bürgerliche Gesellschaft ${ }^{5}$, es considerada la obra más "realista" de Hegel, pero no atrajo la atención que

\footnotetext{
${ }^{1}$ HEGEL, Principios de la Filosofía del Derecho. OBS. al parágrafo 209. Es revelador que en plena "travesía" por el núcleo social de la eticidad, cuando se plantean las ineludibles relaciones entre las necesidades y el trabajo, el derecho se plantee como algo universalmente reconocido, sabido y querido.(209). Recordemos aquí a "nuestro ilustrado" Juan de Mairena, "..por mucho que un hombre valga, nunca tendrá valor más alto que el de ser hombre". Antonio Machado, Juan de Mairena. VI. Madrid,2004.(Alianza)

2 Para los "Grundlinien der Philosophie des Rechts," hay tener en cuenta la edición de Johannes Hoffmeister; (reimp),Hamburg,1967. Para los controvertidos "Zuzätsen", que no se contienen en esta edición, hemos tenido en cuenta la edición de George Lasson, Leipzig,1930. Para la edición castellana, la traducción de Juan Luis Vermal, "Principios de la filosofía del derecho". Buenos Aires, 1975. Muy reciente, la edición castellana de $\mathrm{M}^{\mathrm{a}}$ del Carmen Paredes Martín. Madrid, "Líneas fundamentales de la Filosofía del Derecho". Madrid, 2010.(Gredos)

3 "Principios", p.15.

${ }^{4}$ Grundlinien, Parág. 1. Para la reivindicación de esta idea contra el viejo "derecho germánico", el espléndido "Los orígenes del derecho burgués". (Hegel contra Savigny"), de Aldo SCHIAVONE. (Edersa). Madrid,1986. [Todos los parágrafos de la obra de referencia de Hegel, Grundlinien der philosophie des Rechts; irán en negrilla]

${ }^{5}$ En los "Grundlinien", la sección dedicada a la sociedad civil comprende desde el parágrafo 182 al 256 inclusive. Es interesante constatar cómo los traductores más conocedores de la obra de Hegel no traducen "sociedad civil", sino "sociedad burquesa". Esta denominación está llena de significación histórica.
} 
suscitaron sus reflexiones más específicamente políticas. Ni sus activos seguidores de la "hegelsche Linke", ni los primeros estudiosos de su "Sistema" repararon detenidamente en el tema. La gran excepción, en este sentido, se concretó en los estudios de Paul Vogel, que fueron un estímulo para las numerosas indagaciones ulteriores ${ }^{6}$. Es importante seguir la advertencia de Haym: Bucear en la historia de los conceptos para hallar una cabal comprensión de los mismos. Esta advertencia la reitera Gadamer, gran conocedor de la obra de $\mathrm{Hegel}^{7}$,"sigo, desde hace tiempo, el principio metodológico de no emprender nada sin rendir cuentas de la historia que se esconde detrás de los conceptos"8.

Hegel vive con intensidad la irrupción del mundo moderno. Y, en línea con la "Fenomenología", experimenta la conciencia infeliz. En este caso, el drama del individuo que ya no puede sino ser moderno, pero que observa con melancolía el "ethos" del mundo antiguo. Aspiraba a satisfacer en la propia persona el encuentro entre la universalidad y la unidad de lo real. Observa lúcidamente la escisión que, de manera multiforme, se reflejaba en todos los campos: en la especulación, entre los sentidos y la razón; en la moral, entre la conciencia del deber y la propia utilidad social; en la vida religiosa, entre la libertad del sentimiento y la decadente autoridad institucional de la iglesia, disociada del tiempo histórico. La revolución francesa, destruyendo el Estado monárquico, había destruido la última apariencia unitaria entre virtud y política. Además, había proyectado una intensa luz sobre la nueva y compleja vida de las relaciones económicas y jurídicas. En esta nueva forma de existencia social, se reflejaban fielmente las aspiraciones de la burguesía, así como el enconamiento de su conflicto con el despotismo regio, culpable de representar una razón de Estado distinta de la privada ${ }^{9}$. El gran contraste lo constituyen los intereses y la finalidad del individuo, a cuya defensa debe subordinarse la organización política ${ }^{10}$. En la absurda impotencia política del imperio, cuyas cenizas aventaban los nostálgicos del antiguo régimen, destacaban, con más fuerza si cabe, las remodelaciones político-administrativas, que hallaban un eco

\footnotetext{
${ }^{6}$ VOGEL,P., "Hegel Gesellschaftsbegriff und seine geschichtliche Fortbildung durch L:Stein, Marx,Engels und Lasalle". Berlin,1925. Unos años antes, F. TÖNNIES, en su clásico "Gesellschaft und Gemeinschaff"'(2aed.,1912), ya había referido la sociedad civil hegeliana a "la sociedad moderna de contrato, canje y trabajo". (p.25).

"HAYM, R, Hegel und seine Zeit", 1962, cit, sobre todo en la "Einleitung".

${ }^{8}$ GADAMER,H.G.,"Subjetividad e intersubjetividad. Sujeto y persona". En "El giro hermenéutico". Madrid, 1995. (Cátedra), p.12.

${ }^{9}$ Una espléndida caracterización y síntesis de este cuadro histórico en DROZ, J.,"L'Allemagne et la Revolution française". Paris

${ }^{10} \mathrm{G}$. SOLARI, II concetto de societá civile in Hegel, en "Rivista di Filosofia, XXI,1931,pp.299347. Nos hemos atenido a la reproducción de este texto en la recopilación que realizó Luigi Firpo de los escritos de Solari, "Filosofia política", Bari, 1974. pag. Cit,227. Muy relevante para la delimitación contemporánea del concepto de sociedad civil y sus orígenes, el estudio de Manfred RIEDEL, "Hegels Begriff der bürgerlichen Gesellschaft und das Problem seines geschichtlichen Ursprung", Archiv für Rechts- und Sozialphilosophie, 48(1962). Después en "Materialen zu Hegels Rechtsphilosophie". Frankfurt /M 1975,II, 247-275. Hay t.c., "El concepto de la sociedad civil en Hegel y el problema de su origen histórico", en los "Estudios sobre la Filosofía del Derecho de Hegel". Edición de Gabriel Amengual Coll. (CEC), Madrid, 1989.BOBBIO, N. "Sulla nozione de società civile"."De homine" XXIV-XX(marzo 1968).R.KRONER,"Die bürgerliche Gesellschaft im Hegels System". Archiv für angewande Soziologie IV.(1931).
} 
favorable en la difusa conciencia de libertad ${ }^{11}$. Ésta se hallaba unida a la nueva configuración que cobran la producción y distribución de bienes. Esta conciencia produjo, como es sabido, una evidente ambivalencia respecto a la dominación francesa que contribuyó, de forma importante a eliminar los vestigios del feudalismo en la Alemania anterior a $1848^{12}$.

En este marco, HEGEL va a prestar una singular atención a las teorizaciones clásicas e incipientes de los economistas ingleses y de sus ilustres precedentes escoceses. En HOBBES, y con distinta formulación en LOCKE, se acentúa la tendencia, habitual desde GROCIO, a identificar un "estado natural prepolitico" como el marco de libre despliegue de la actividad económica y, también de pugna entre los intereses privados. De forma muy diferente a la negativa visión hobbesiana, otros teóricos observaban en dicho "estado natural" el verdadero estado originario, en el que todos los hombres razonables convenían y convivían aun sin la presencia de un pacto de unión explícito. En este terreno, resulta muy sintomática la crítica virulenta que Hegel desarrolla contra la obra de C.L.von HALLER, "Restauration der Staatswissenschaff". Justamente al comienzo de la sección dedicada al Estado ${ }^{13}$, Hegel considera inauditas las analogías que el autor suizo establecía entre una cosmovisión "naturalista" y el ámbito político jurídico según las cuales, "el poderoso debe oprimir al débil tal como ocurre en el reino animal". Pues bien, von HALLER considera a la sociedad civil un concepto revolucionario de la filosofía de la ilustración: Al designar a los hombres como miembros iguales y libres de una "sociedad civil", distinta de las "sociedades naturales" se habría disuelto, insiste von Haller, "el vínculo social". ${ }^{14}$ Respecto a las hipótesis de las formas sociales "naturales", así como a los utopismos "originalistas", HEGEL es contundente: la libertad sólo existe históricamente ${ }^{15}$.

Hay que tener en cuenta que, ya desde la segunda mitad del XVIII, se había popularizado la expresión "civil society" a raíz de la obra del escocés FERGUSON "An essay of the history of civil society", aparecida en $1767 \mathrm{y}$ traducida al alemán un año después ${ }^{16}$. En los "Grundlinien", HEGEL diferencia

\footnotetext{
11 MARCUSE, H., Razón y Revolución. Hegel y el surgimiento de la teoría social. Madrid,1971.Págs. 170 y ss.

12 "En un clima de extensión de la igualdad civil y de la libertad religiosa se producen la abolición del diezmo y de los derechos feudales, así como la proscripción de la venta de cargos eclesiásticos; se suprimen las guildas y se multiplica una burocracia unida a criterios administrativos racionalistas y liberales". G. LEFEVRE, Napoleón. Paris,1935. Pág.428. Sobre la significación y alcance del contexto de la revolución, RITTER, J., Hegel und die Französische Revolution (1957).

${ }^{13}$ Parágrafo 258.

${ }^{14}$ RIEDEL, El concepto de la sociedad civil en Hegel, cit., 198,199.

${ }^{15}$ Observemos la importancia del parágrafo 57 de los Grundlinien. Según Hegel, no se puede argumentar a favor o en contra de la libertad del hombre desde un supuesto estado natural, sino siempre desde la historia.:Ia libertad sólo existe históricamente.En la Obs. al parágrafo 194, escribe Hegel, "Es una falsa opinión la representación de que el hombre vive en libertad respecto a la necesidades en el llamado estado natural, en el que tendría las llamadas simples necesidades naturales (...).”.

${ }^{16}$ La obra de Adam FERGUSON tuvo un gran influjo en ADAM SMITH, singularmente en su concepción sobre "la división del trabajo".(El ensayo de Ferguson está traducido al castellano por Juan Rincón Jurado. CEC. Madrid, 1974. Hay una edición reciente, Madrid,2010. Trad.de $M^{\underline{a}}$ Isabel Vences./Akal). G. JELLINEK (Allgemeines Staatslehre, $1^{\text {a }}$ ed. 1900), recuerda a A.L. SCHLÖZER( Allgemeines Staatsrecht, Göttingen,1793) como el primer autor alemán que
} 
expresamente a la sociedad civil(o, mejor, sociedad burguesa) del Estado. Considera la confusión de esta sociedad con el Estado como un error reiterado de la mayoría de los tratadistas modernos de derecho público ${ }^{17}$. $\mathrm{Y}$, sin embargo, la evolución histórica de la clásica koinonia,-communitas-, como la forma de unión o asociación es compleja en extremo hasta que, a finales del XVIII, se comienzan a diferenciar Estado y sociedad con carácter general. Como se ha indicado respecto a la obra de HEGEL, esto es claro en la Filosofía del Derecho, pero no antes ${ }^{18}$. HEGEL observa las nuevas formas sociales con una dosis de conocimientos económicos poco común ${ }^{19}$. A la teorización hegeliana ya no le era útil el hombre abstracto de los empiristas y iusnaturalistas y, aún menos, su mítico "estado de naturaleza"; por el contrario, debería asumirse como expresión característica de la nueva civilización burguesa el hombre concreto de los economistas, desvinculado de cualquier dependencia o tutela, en plena independencia respecto de sus semejantes y despreocupado de cualquier tipo de asociación para objetivos comunes; preocupado, pues, tan sólo de sí y de satisfacer sus necesidades reales ${ }^{20}$.

Cuando HEGEL habla de la libertad, "no comienza por una disertación "metafísica" sino por un análisis de la libertad concreta, bajo su forma más primitiva, más simple y más abstracta, pero en la cual también aparece objetivamente, como forma del derecho(1). Aquí aparece una individualidad que aspira a convertirse en sujeto y en persona, pero que aparece cargada de determinaciones. Se trata de la conciencia de libertad que se expresa como tal, atravesando la negatividad de esa finitud: "de este modo el sujeto es persona. En el concepto de personalidad se expresa que "yo, en cuanto este", soy finito y perfectamente determinado en todos los aspectos, (tanto en lo que respecta al arbitrio interior, instintos y deseos, como en lo que hace a la existencia exterior e inmediata), y, a pesar de ello, en libre relación consigo

distingue "Estado" y "Sociedad". Esta última es, para SCHLÖZER, una comunidad jurídica sin Imperium, determinada por exigencias económicas. Según SOLARI,-II concetto, cit.-es verosímil que Hegel conociese directamente las obras de FERGUSON y de SCHLÖZER.

17 FETSCHER, I." Actualidad y significado del concepto de sociedad civil en el pensamiento político de Hegel". Revista "Sistema", no10.(t.c. de Ignacio Sotelo). Pág.32

${ }^{18}$ El propio FERGUSON que tanto contribuyó a popularizar la expresión tenía un concepto tradicional de la sociedad, pero ya difuminado.."Atomístico", como diría el Hegel de la Enciclopedia. "El Estado o la sociedad civil, civitas sive societas civile sive res publica, tal era la fórmula clásica de la filosofía europea tal como tenia vigencia antes de la separación entre Estado y sociedad. Pero esta unión o fusión,-que no confusión-, está al comienzo del Libro I de la "Política" de ARISTÓTELES,-(Madrid,1977. Ed. de Garcia Gual/Pérez García)-, "Así que todas las comunidades pretenden como fin algún bien; pero sobre todo pretende el bien superior la que es superior y comprende a las demás. Esa es la que Ilamamos ciudad y comunidad cívica". Sobre esto, RIEDEL, "El concepto", cit, p.201. La expresión kantiana Staatsbürger(ciudadano) fue importante en esta evolución y, sin embargo, no fue bien acogida. Hay que recordar que Kant jugaba, como THOMASIUS y WOLFF, con la clásica contraposición entre "societas civilis" y "societas domestica".

${ }^{19}$ ANDLER, Les origines du Socialisme d'Etat en Allemagne, Libro II, cap.I: "Le smithianisme hégélien", cit, p.145. Andler aseguraba que la competencia de Hegel en materia económica era cierta y profunda, debida en parte a la influencia familiar y, en parte, a sus estudios de la "nueva ciencia económica" en las obras de James STEUART, Adam SMITH y Jean-Baptiste SAY.

20 "la persona concreta que es para sí un fin particular, en cuanto totalidad de necesidades y mezcla de necesidad natural y arbitrio es uno de los principios de la sociedad civil"(par.182). 
mismo que, de esta manera, me sé en la finitud como infinito, universal y libre ${ }^{21}$.

El individuo aparece ya como persona en la realización de su voluntad empírica y natural, en tanto que individuo. Es el derecho del individuo en tanto que tal ${ }^{22}$; su esfera exterior; el derecho de propiedad ${ }^{23}$. La sociedad civil se presenta, por tanto, como unión de los miembros como individuos independientes en una universalidad formal desarrollada por medio de sus necesidades" 24 . Aquí ya se produce una vigorosa delimitación del "télos" económico $^{25}$. Y una propiedad, específicamente constitutiva del individuo, y de su relación mediadora con los otros individuos, bajo las formas contractuales ${ }^{26}$. Hegel está "atravesando" las determinaciones negativas en su trayecto desde la particularidad hacia la universalidad. Aquí, está claro, hay un extravío y una lejanía de la ética: "Lo ético está aquí perdido en sus extremos y la unidad inmediata de la familia se ha dispersado en una multiplicidad(..)". La particularidad por sí, por una parte, en cuanto satisfacción en todas direcciones de sus necesidades, del arbitrio contingente y del gusto subjetivo, se destruye a sí mismo en su gozo y destruye su concepto sustancial(... $)^{27}$.La sociedad civil ofrece en estas contraposiciones y en su desarrollo el espectáculo del libertinaje y la miseria con la corrupción física y ética que es común a

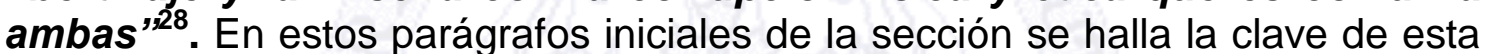
sociedad, cuyos componentes son "personas privadas que tienen como finalidad su propio interés"(187); personas que, no obstante ese "fin egoísta, condicionado de ese modo por la universalidad fundan un sistema de dependencia multilateral".(183)

Ya puede apreciarse una cierta diferenciación y "espiritualización de las necesidades". El hombre, desarrollando sus potencias, puede sustraerse a la dura servidumbre de las necesidades y satisfacer exigencias espirituales cada vez más altas; el desarrollo moral puede producirse. Aquellas necesidades pierden progresivamente su carácter individual para revestirse de un carácter social. Esto significa para el hombre salir de sí, ponerse en relación con otros hombres e intercambiar los productos de su actividad ${ }^{29}$.

${ }^{21}$ Grundlinien, 35.

22 "la persona, para existir como idea tiene que darse para su libertad una esfera exterior"(41). "Lo racional de la propiedad no radica en que sea la satisfacción de necesidades, sino en que supera la mera subjetividad de la personalidad" (41; agregado)

${ }^{23}$ E. WEIL, Hegel y el Estado, Buenos Aires, 1970. Págs.47,48.

24 Par.157.

${ }^{25}$ KOFLER, L.,Contribución a la historia de la sociedad burguesa, Buenos Aires,1974. Pág. cit, 411.

26,"La propiedad, de la cual el lado de la existencia o la exterioridad, ya no sólo es una cosa, sino que contiene en si el momento de una voluntad(por lo tanto distinta), se establece por medio del contrato. Este es el proceso en el que se expone y media la contradicción de que yo, existente por mi, soy y permanezco propietario con exclusión de la voluntad ajena en la medida en que junto con la idéntica voluntad del otro, dejo de ser propietario."(Grundlinien, 72)

27 "En la sociedad civil cada uno es fin para si mismo y todos los demás no son nada para él. Pero sin relación con los demás no puede alcanzar sus fines; los otros son, por lo tanto, medios para el fin de un individuo particular".(182; Agregado)

28 "Grundlinien", 184, agregado y 185.

${ }^{29}$ CERRONI,U.," Societá civile e Stato político in Hegel'. Bari,1974. Sobre todo, los capítulos 2 y 3. Págs.38 y ss. 
Al hombre "natural" de los economistas y iusnaturalistas, Hegel contrapone el hombre como sujeto social ${ }^{30}$, que consigue trascender la esfera inmediata de su particularidad y establecer un sentido liberador: "Puesto que en las necesidades sociales en cuanto unión de las necesidades inmediatas o naturales y las necesidades espirituales de la representación, es esta última la preponderante y hay en el momento social un aspecto de liberación". Es importante reparar en los esfuerzos de Hegel por considerar provisional la "negatividad" de los antagonismos sociales, pero en absoluto en ignorarlos o cancelarlos. Su esfuerzo reside esencialmente en captar el momento del hombre que, como persona social, puede ser sujeto moral sin llegar aún a ser ciudadano, "esta liberación es formal, pues la particularidad de los fines sigue siendo el contenido básico" ${ }^{1}$.

En estas tensiones entre la necesidad y la libertad, traza Hegel en el parágrafo 188, las mediaciones o momentos necesarios en el tránsito desde la sociedad civil hacia la eticidad o civilidad ${ }^{32}$; es decir, hacia el Estado. Para una adecuada comprensión de lo que son las dimensiones esenciales de la sociedad civil para Hegel, es muy importante no olvidar que ésta se halla ya dentro de la eticidad; atravesada por ella, es decir, por un "conjunto de mediaciones institucionales que esta sabiduría práctica debe atravesar para que la justicia merezca realmente el título de equidad" ${ }^{33}$. Y así, aquellos momentos, son: A)El Sistema de las necesidades; B)La administración de justicia; y C) El poder de policía y la corporación(188). Hay que observar que la imperfección de la sociedad burguesa, o "Estado exterior", como también Hegel la denomina, ${ }^{34}$ no consigue que la identidad ética se consume en la unidad de lo general y lo particular, como sí ocurre en el Estado ${ }^{35}$. Aquí tenemos pues, a la vista, una clara toma de posición, una intervención y un papel activo de la razón frente a la contingencia de la sociedad civil. Se están traspasando los "sagrados límites" que el liberalismo había trazado en torno al

\footnotetext{
${ }^{30}$ La voluntad libre está unida a la razón: no es la voluntad que desea cualquier cosa. Lo absoluto no es sustancia sino sujeto; 10 absoluto no es lo primero, sino que es esencialmente resultado".

31 "Grundlinien", 195.

${ }^{32}$ La traducción de la "Sittlichkeif" hegeliana no ha estado exenta de problemas. Es interesante conocer el pasaje que Hegel dedica a la disociación moralidad-eticidad en el párrafo final del parágrafo 33 de los "Grundlinien", con una referencia explícita al "lenguaje kantiano". Por lo demás, la Sittlichkeit condensa el gran salto que Hegel da respecto del liberalismo moral kantiano. Uno de los mayores conocedores de la obra de Hegel, Jose M. ${ }^{a}$ RIPALDA,- traductor de escritos esenciales de este pensador- propuso traducir "Sittlichkeit" por "Civilidad".

${ }^{33}$ RICOEUR, P. "Sí mismo como otro". Madrid, 1996. Pág. 271.

34 "En su realización, el fin egoísta, condicionado de ese modo por la universalidad, funda un sistema de dependencia multilateral por el cual la subsistencia, el bienestar y la existencia jurídica del particular se entrelazan con la subsistencia, el bienestar y el derecho de todos, se fundamentan en ellos y sólo en ese contexto están asegurados y son efectivamente reales. Se puede considerar este sistema en primer lugar como estado exterior, como el estado de la necesidad y el entendimiento". Grundlinien, 183.

35 "El Estado es la realidad efectiva de la libertad concreta. Por su parte la libertad concreta consiste en que la individualidad personal y sus intereses particulares tengan su total desarrollo y el reconocimiento de su derecho(en el sistema de la familia y de la sociedad civil)al mismo tiempo que se convierten por sí mismos en interés general.."Grundlinien, 260. La referencia es explícita a este parágrafo en LÖWITH, K., Von Hegel zu Nietsche.ll Parte. T.c. Buenos Aires, 1968.
} 
individuo. Para Hegel, resulta obvio que la deseable unión entre lo particular y lo general no se produce libremente, sino con la coacción de las relaciones objetivas $^{36}$.

Resulta curioso, pero no casual, que la mayor parte y las más conocidas descripciones de la dinámica de la sociedad inglesa del primer capitalismo, se halle en la tercera parte de esta sección, que se desarrolla a partir del parágrafo $\mathbf{2 3 0}$ hasta el tránsito hacia el Estado. El hombre, que según su existencia inmediata es algo natural(p.57), exterior a su concepto, denso y lleno de significaciones, tiene necesidades precisamente como tal hombre; los fines de la finitud(123). No como persona, ni como sujeto, ni como miembro de la familia, ni como ciudadano. Aquí, en el punto de vista de las necesidades es la representación concreta que se llama hombre. ${ }^{37}$ Ahora bien, hay que atender la radical exigencia de historicidad del sujeto hegeliano, la verdadera sustancia de su pensamiento y, en consecuencia, la satisfacción de las necesidades cobra siempre una modalidad social específica. Las necesidades se multiplican y diversifican ${ }^{38}$.

Hay una primera articulación del sistema de las necesidades en el propio concepto de necesidad: necesidad subjetiva, que alcanza su objetividad, es decir su satisfacción, por medio de cosas exteriores que son igualmente la propiedad y el producto de otras necesidades y voluntades(189). Estamos en un ámbito de aparente racionalidad que, en realidad, es el ámbito del entendimiento. Estamos en el terreno de la economía política; una de las ciencias que ha encontrado en la época moderna su terreno propio(189;Obs.). Como ya se constató en el derecho abstracto, la elaboración de los medios, lo que el hombre produce, se subsume en el cuadro general apriorístico de la apropiación jurídica $^{39}$. Necesidad, satisfacción, propiedad, son modos todos ellos mediados por el trabajo: "La mediación que prepara y adquiere para las necesidades particularizadas medios igualmente particularizados, es el trabajo, que por medio de los más diversos procesos especifica esos múltiples fines para el material inmediatamente proporcionado por la naturaleza. Esta elaboración da a los medios su valor y su utilidad, y hace que los hombres, en su consumo, se relacionen principalmente con producciones humanas; y que lo que propiamente consuman sean esos esfuerzos. ${ }^{40 " . ~ E l ~ f a c t o r ~ t r a b a j o ~ s e ~ h a l l a ~}$ en el centro de la dinámica de cualificación social de los medios primarios. El trabajo no sólo valoriza económicamente, sino también racional y moralmente los datos y las cosas del mundo externo. Estas cosas se especifican a través del trabajo y adquieren la variedad y multiplicidad de las necesidades. El trabajo se especializa y divide dotando de relevancia a la fuerza socializadora

\footnotetext{
${ }^{36}$ FETSCHER, "Actualidad y significado", cit, 34.

${ }^{37}$ P.190, Obs.

${ }^{38}$ P.191. Observemos la incuestionable "actualidad" de las lecturas y reflexiones hegelianas en el Agregado a este parágrafo: "Lo que los ingleses llaman confortable es algo inagotable y que continua al infinito, pues toda comodidad muestra nuevamente su incomodidad y las invenciones no llegan nunca a un fin. La necesidad no existe por lo tanto para los que la poseen de un modo inmediato, sino que es producida por quienes buscan una ganancia con ella".

${ }^{39}$ CERRONI, Stato político, cit., 27.

40 196. En la Obs. a este parágrafo, el matiz de la nueva ciencia económica: "Es insignificante el material que no necesita ser elaborado".
} 
de la actividad humana, "en la multiplicidad de los objetos y de las determinaciones afectados se desarrolla la cultura teórica"(197). No podemos sino admirarnos de la relevancia que Hegel otorga a dos rasgos estructurales de la forma social contemporánea: "Lo universal y objetivo del trabajo reside sin embargo en la abstracción que ocasiona la especificación de los medios y las necesidades, y que, por lo tanto, también especifica la producción y produce la división del trabajo" ${ }^{\prime 1}$.

En aquella abstracción emerge la conexión con la abstracción de la igualdad política. Sin embargo, en la específica referencia de la sociedad civil, "...esta diversidad se muestra en esta esfera de la particularidad en todas las direcciones y en todos los estadios, y unidas con las demás contingencias y arbitrariedades de otro origen, tiene como consecuencia necesaria la desigualdad de los patrimonios y las habilidades de los individuos.."(200). Es importante en extremo tener conciencia de la distinta configuración que cobra la idea de igualdad al atravesar los distintos momentos. Ésta es, en esencia, la labor de la filosofía, "Entender que lo que es, es el objetivo de la filosofía puesto que lo que es la razón "42 Por su parte, la razón no es pura idealidad, abstracción, esquema, deber ser; es lo que real y concretamente existe. Es por lo que Hegel entiende que "pertenece al entendimiento vacío que toma su abstracción y su deber ser por lo real y racional, el oponer la exigencia de igualdad al derecho objetivo de la particularidad del espíritu incluido en la idea. Este derecho, no sólo no elimina en la sociedad civil la desigualdad de los hombres puesta por la naturaleza,-elemento de desigualdad-, sino que la produce a partir del espíritu y la eleva a desigualdad de la habilidad, al patrimonio e incluso a la cultura moral e intelectual."(200;Obs.). En consecuencia, Hegel después de haber ponderado la inmensa utilidad ética y política de determinadas mediaciones, retorna a una concepción atomística de la sociedad civil $^{43}$ : una agregación de individuos que se relacionan recíprocamente produciendo una estructura beneficiosa para todos. Aquí se refleja explícitamente el esquema de invisibilidad del automatismo social del beneficio de Adam SMITH: un ordenamiento o designio ocultos que convierten

\footnotetext{
${ }^{41}$ 198. "El trabajo del individuo se vuelve así más simple y mayor la habilidad en su trabajo abstracto, así como mayor la cantidad de su producción. Al mismo tiempo, esta abstracción de la habilidad y de los medios completa y hace totalmente necesaria la dependencia y la relación recíproca de los hombres para la satisfacción de sus restantes necesidades. La abstracción del producir hace además que el trabajo sea cada vez más mecánico y permite que finalmente sea eliminado y ocupe su lugar la máquina"

${ }^{42}$ HEGEL, Grundlinien, Prefacio, 24. En cuanto es real, lo finito no es tal, sino que es el mismo infinito. La realidad, tal como es, se justifica enteramente y cualquier pretensión de contraponer a la misma un deber ser cae en la nada. El ser y el deber ser coinciden. (Sobre esta cuestión, ABBAGNANO, Historia de la filosofía, III; Barcelona, 1993; pp.90-93) Hay que matizar esto: Evidentemente, aquí la noción de ser es entitativa; existencial. No se corresponde con la metacategoría aristotélica del Ser.
}

\footnotetext{
${ }^{43}$ Estamos ante la concepción liberal primigenia: De acuerdo con los principios nominalistas, la sociedad,-concepto abstracto-, no designa nada fuera del conjunto de sus miembros individuales, "comunitas non est una vera persona, sed est plure verae personae(....),civitas est verae res plures, non unica"(W.OCKHAM.; Opus XC dierum, cap.6).
} 
una pulsión egoísta en un resultado útil ${ }^{44}$; así, también Kant señalaba las beneficiosas consecuencias sociales que se derivaban de las pulsiones egoístas ${ }^{45}$. "En esta dependencia y reciprocidad del trabajo y de la satisfacción de las necesidades, el egoísmo subjetivo se transforma en una contribución a la satisfacción de las necesidades de todos los demás. Le convierte en la mediación de lo particular por lo universal, en el movimiento dialéctico en el que cada uno, al ganar, producir, gozar para sí, produce y gana para todos los demás. Esta necesidad que reside en el entrelazamiento multilateral de la dependencia de todos, es, ahora para cada uno, el patrimonio general y permanente. ${ }^{46 "}$. Así pues, actuando por su interés privado, el hombre actúa para todos. El salto de HEGEL es inmenso y, definitivamente, deja atrás el XVIII, "como mero hombre, es decir, natural, el hombre es un ser de necesidades, y como ser de necesidades es hombre privado, o sea, ciudadano en cuanto"bourgeois"(190;Obs.). Hombre y ciudadano no se hallan ya, como en el siglo XVIII, uno frente al otro, sino que en la moderna sociedad burguesa el burgués encierra el hombre dentro de sí" ${ }^{47}$.

Ciertamente, aquí se detecta una manifiesta inversión lógica. En una primera lectura, la sociedad aparece como un universo indiferenciado en el que Hegel inserta al "hombre-persona" como un auténtico predicado de la moderna propiedad privada ${ }^{48}$. Este supuesto apriorístico va ser mediado con los datos positivos de la socialidad de su momento histórico; y así, aparecerán el contrato y el patrimonio. Más específicamente, la propiedad, como expresión inmediata de la voluntad personal $(\mathbf{4 1 , 4 2 )}$, en una organización desarrollada, cede lugar al patrimonio. Ahora bien, así como la familia se disuelve en la sociedad civil, el patrimonio familiar, cambia de función desde el momento en el que una organización más potente permite constituir y conservar un patrimonio

\footnotetext{
44 "Adam SMITH que había reducido el valor al trabajo social, expresaba rotundamente el punto de vista del capitalista, considerando a la vez,-incongruentemente-,los beneficios de éste como parte "natural" del precio de una mercancía". Jose M $M^{a}$ RIPALDA, La nación dividida. Madrid,1978. (FCE). Pág.74.

45 "Los impulsos naturales, las fuentes de la insociabilidad y de la resistencia absoluta, de donde nace tanto daño, pero que, al mismo tiempo, conducen a nuevas tensiones de la fuerzas y, así, a nuevos desarrollos de las disposiciones naturales, delatan también el ordenamiento de un sabio creador y no la mano chapucera o la envidia corrosiva de un espíritu maligno". KANT; Idea de una historia universal en sentido cosmopolita. 4를 Principio. En "Filosofía de la Historia" Reimp. Madrid,1989. (FCE)

${ }^{46}$ 199. Aquí, aparece la referencia a la familia del parágrafo 170 , en la que el patrimonio se convierte en algo ético, "la familia no sólo tiene propiedad, sino que en cuanto persona unilateral y perdurable, aparece la necesidad y la determinación de una posesión permanente y segura, de un patrimonio".

${ }^{47}$ RIEDEL; El concepto, cit., 207.

${ }^{48}$ HEGEL es muy analítico y descriptivo respecto a los momentos del "hombre-persona" en la sociedad civil: "En el derecho el objeto es la persona; en el punto de vista moral, el sujeto; en la familia, el miembro de la familia, en la sociedad civil en general, el ciudadano(como"bourgeois"); aquí, en el punto de vista de las necesidades (cf, 123; Obs), es la representación concreta que se llama hombre. Recién aquí y sólo propiamente aquí puede hablarse en ese sentido de hombre. (190; Obs). Es interesante recordar en este punto a Karl LÖWITH, "Hombre, en el verdadero sentido de la palabra, es, por tanto, sólo el bourgeois, el sujeto de las necesidades; esta simple particularidad, en oposición a su íntima universalidad. Del hombre en el sentido de la filosofía sucesiva,-de FEUERBACH, RUGE, MARX, STIRNER, KIERKEGARD,-se habla en HEGEL sólo desde el punto de vista de la sociedad civil". Von HEGEL zu NIETZSCHE, cit. 423.
} 
social $^{49}$. Hay que destacar que la caracterización hegeliana del patrimonio "general y permanente"(199), parece gozar, en su extraordinaria dimensión, de una indudable cualidad estatal ${ }^{50}$. El "impasse" de la indagación hegeliana es aquí notable: la sociedad se configura como una voluntad agregada que ha cambiado la forma de la comunicación, de la circulación y del cambio mientras que la producción parece configurarse como una relación extrasocial entre el hombre y la cosa ${ }^{51}$. Después, la historia tal cual, con todas sus determinaciones, irrumpirá con toda la empirie característica de la sociedad civil $^{52}$, con todo su "conjunto orgánico de diferencias", en el que se articulan los estamentos. No obstante, no nos engañemos respecto al concepto unificador y estructurado de la forma social que se describe(229): la sociedad civil que HEGEL recoge y anticipa es la de finales del siglo XIX, pero no sería civil si no estuviera ordenada y conjuntada jurídica, ética y políticamente ${ }^{53}$.

Así llegamos al Estamento, que, en la Rechtsphilosophie hegeliana, no hay que confundir con el estamento feudal caracterizado por una posición jurídica propia y cerrada, constitutiva de la rígida estratificación del cosmos medieval. Los estamentos medievales, no se desarrollan en relación con la singularidad de las relaciones productivas sino que expresan y forman parte de un orden de legitimidad teocrática y un cuadro político inmediato y descendente. En el tejido estamental, era tan determinante el arbitrio de los gobernantes como el hecho del nacimiento. De forma muy diferente, en HEGEL, se trata de un estamento profesional que compatibiliza la libertad económica con un régimen asociativo abierto ${ }^{54}$ : "La representación que vuelve a disolver las comunidades ya existentes en aquellos círculos cuando éstos llegan al elemento político, es decir al punto de vista de la más elevada universalidad concreta, separa la vida civil y la vida política, dejando a ésta, por así decirlo en el aire, pues su base sería únicamente la abstracta individualidad del arbitrio y la opinión, por lo tanto, lo contingente y no un fundamento firme y justificado en y por sí. $(303 ; \text { Obs. })^{55}$. Sin embargo, importa sobre manera advertir que esta categoría

\footnotetext{
${ }^{49}$ WEIL, Hegel y el Estado, cit, 115.

${ }^{50}$ FETSCHER, Actualidad y significado, cit., 35.

${ }^{51}$ Aquí la referencia es explícita al derecho privado romano. Al individuo libre, a diferencia del no libre, en cuanto persona que tiene capacidad jurídica, y que, en consecuencia, ejercita su derecho de disponer de cosas y, en su relación con las cosas, se relaciona con otras personas.(40). En el 44, hay una expresión del liberalismo absoluto: el derecho de apropiación del hombre sobre toda cosa. En el 44; Agregado: las cosas no tiene por sí mismas un fin; tienen el que les doy. Hay un antropomorfismo absorbente...

${ }^{52}$ CERRONI, Stato político, cit., 52.

${ }^{53}$ RIEDEL, El concepto, cit., 216,217.

54 Importa precisar la significación, la estricta y también otra, más laxa, de los "Stände" hegelianos, como elemento histórico y conceptual, que cobra significaciones matizadamente distintas en función del contexto en el que se inserten. A este respecto, podremos comprobar cómo los "Stande" se transforman en segmento de la vida parlamentaria. El traductor de nuestra edición de referencia, Juan Luis VERMAL, a propósito de la traducción del "Stand", escribe: Traduzco "Stand" por clase cuando está utilizado en sentido social y por estamento cuando lo está en sentido político-representativo(asamblea de los "estamentos" o "estados"), parágrafos 300 y ss.(Principios, p.241; nota $n \div 57$ ), Hay que recordar, no obstante, que ambos sentidos, que el lenguaje posteriormente separó, están para HEGEL estrechamente unidos., como se pone de manifiesto en el parágrafo 303.

${ }^{55}$ Muy expresivo el párrafo final de este parágrafo 303: "Si bien en las representaciones de esas llamadas teorías se han separado completamente las clases(Stände) de la sociedad civil, de los estamentos en sentido político(in politischer Bedeutung), la lengua alemana ha
} 
está al servicio de la teorización hegeliana de las clases. Las clases sociales expresan las diferencias: "sistemas particulares de necesidades, medios y trabajo, de modos de satisfacción y de cultura teórica y práctica, en los que se reparten los individuos dando lugar a la diferencia de clases."(201). Una clase va sedimentando en el individuo unos hábitos, concepciones, formas,-un "imaginario" que diríamos con una categoría contemporánea ${ }^{56}$, que constituyen sus sentimientos y sus previsibles conductas. En el clasismo de la sociedad civil es el mecanismo económico es que adquiere modalidad social. Obviamente, HEGEL yuxtapone a este mecanismo la eticidad en la que se mueve, y a la elección que nace de la subjetividad, para apartarse de nuevo de la visión atomística, liberal, que continuamente se introduce. Hay una depreciación de cualquier concepción de la persona aislada; de la persona privada en cuanto tal. Para nuestro autor, esta persona aislada carecería de universalidad $^{57}$. Hasta el parágrafo $209^{58}$, HEGEL realiza una descripción de las tres grandes clases sociales: "clase sustancial o inmediata, clase formal o reflexiva y, finalmente, clase universal'(202).

Nuestra pretensión es ser sumarios a la hora de recoger el clasismo de la sociedad civil. No obstante, hay que apuntar indicios iluminadores sobre la forma social contemporánea, característicos de la inmensa riqueza del texto hegeliano. De forma similar a los fisiócratas, HEGEL consideraba a la clase de pequeños agricultores que poseían y cultivaban directamente el suelo, como tal clase sustancial, con sentimientos de pertenencia y subordinación a la tierra; con una eticidad natural, inmediata ${ }^{59}$. Frente a esta naturalidad que bordea el

conservado sin embargo en la palabra "Stand" una unión que, por otra parte, existía anteriormente". Por su parte, José Ma RIPALDA, en su traducción del escrito de juventud de MARX, "Kritik des hegelschen Staatsrechts", señala, "El factor estamentario("das ständische Moment") o elemento estamentario("das ständische Element) del poder legislativo, sirve en el texto de HEGEL y en el comentario de MARX para designar las Cortes. Aquí la traducción castellana conserva el giro estilístico del original. El término "Cortes" será empleado para traducir "Estados"(Stände) cuando equivalen al "factor estamentario" del poder legislativo. En el parágrafo 304 del texto de HEGEL aparece además otro sinónimo más preciso:"el elemento político-estamentario"("das politisch-ständische Element"). MARX habla también de las Cortes bajo el nombre "sociedad estamentaria"(ständische Gesellschaft") como mediación entre el monarca y la "sociedad burguesa". (Pág.76; nota 57. OME, V, Barcelona, 1978. Critica/Grijalbo) 56 La noción de "imaginario" que juzgamos muy útil, la tomamos de Cornelius CASTORIADIS, "El ascenso de la insignificancia". (Madrid,1998./Cátedra. Págs. 157 y ss.) HEGEL habla de "Gessinung", como "modo global de pensar", idiosincrasia, etc.. SOLARI, II concetto, cit., 237.

57 "Con la expresión de que el hombre debe ser algo, entendemos que debe pertenecer a una clase, pues algo quiere decir que es algo sustancial. Un hombre sin clase es una mera persona persona privada y no está en una universalidad real"(207. Agregado) .

58 Parágrafo en el que comienza la administración de justicia de derecho privado que llega hasta el 229, donde realiza una síntesis clarificadora:"Con la administración de justicia, la sociedad civil en la que la idea se ha perdido en la particularidad y se ha desintegrado en la separación de lo interior y lo exterior, vuelve a su concepto, a la unidad de la universalidad existente en sí con la particularidad subjetiva, aunque ésta sólo en el caso particular y aquella en el sentido del derecho abstracto. La realización de esta unidad en su extensión a todo el ámbito de la particularidad constituye, como unificación relativa, la función del poder de policía, y en una totalidad, limitada pero concreta, la corporación."

203. "por sus condiciones se mantiene sin embargo como un modo de subsistencia mediado en menor grado por la reflexión y la voluntad propia y conserva la disposición sustancial de una eticidad inmediata, basado en las relaciones familiares y en la confianza" 
romanticismo ${ }^{60}$, se encuentra la clase industrial que compendia la modernidad y "depende, para los medios de su subsistencia de su trabajo, de la reflexión y del entendimiento, así como, esencialmente, de la mediación con el trabajo y las necesidades de otro. Lo que produce y goza lo debe fundamentalmente a sí misma, a su propia actividad".(204). Aquí se halla el motor de la centralidad económica característica de la sociedad civil. Aquí hay un salto que va a constituir una característica de la "comunidad perdida" o anhelada y del nuevo orden mercantil que desagrega al mundo antiguo ${ }^{61}$; parece un adelanto de un iluminador pasaje de MARX, "el intercambio de mercancías comienza allí donde las comunidades acaban"62. HEGEL subdivide a esta clase industrial en artesanos ${ }^{63}$, fabricantes y comerciantes. A este estamento se le concede el derecho a organizarse autónomamente en corporaciones ${ }^{64}$. Por encima de la clase agrícola e industrial, encontramos una clase general constituida por aquellos que atienden a las funciones públicas necesarias para mantener el justo equilibrio de los intereses, sin el cual, la sociedad civil no podría subsistir $^{65}$. Esta clase universal(205), simboliza la absorción de su trabajo por parte del Estado, para el interés general, que así le releva del trabajo necesario para satisfacer sus necesidades particulares. En la descripción del tejido clasista de esta sociedad, es frecuente que encontremos el parámetro ideológico de la modernidad tardía, legitimador de los intereses del individuo ${ }^{66}$, cuyo trabajo adquiere significación ética en la clase en la que se encuentra con la universalidad real.

Unos de los elementos singulares de esta sociedad civil, es que uno de sus elementos constitutivos en tanto que Estado exterior(183), sea su dimensión de eticidad relativa. Es sabido que en HEGEL, hay una distinción y contraposición entre la sociedad y el Estado. Sin embargo, esta contraposición relativa está

60 "El hombre recoge aquí con un sentimiento inmediato lo dado, agradece a Dios por ello, y vive con la confiada fe de que esos bienes serán duraderos. Ésta es la disposición libre no dirigida a la adquisición de riqueza(..)" 203. Agregado.

${ }^{61}$ Éste es el supuesto compendiado TÖNNIES y teorizado por WEBER como consumación de la pérdida de sentido de la economía y de la burocracia modernas. El "extravío de la etícidad" que HEGEL reseña en el 184, es premonitorio..

${ }^{62}$ MARX,K, El capital, Libro I, vol.1; pág.107. Madrid,1975 (Siglo XXI). -“'La propiedad privada como origen de la alienación de los hombres entre sí". Esta observación la hace W. BENJAMIN en "El libro de los pasajes", en el cuaderno dedicado a MARX, p.667. Y así cita a este autor:" Las cosas son en y por sí mismas ajenas al hombre, y por eso son enajenables. Para que esta enajenación sea recíproca, los hombres únicamente necesitan aparecer como los propietarios privados de aquellas cosas enajenables y, precisamente por ello, como personas independientes unas de otras. Semejante relación de extrañamiento mutuo no existe sin embargo entre los miembros de ninguna comunidad natural. El intercambio de mercancías comienza donde las comunidades acaban.". MARX, El Capital, Libro I, (edic. de Korsch, 1932, p.99,"El proceso de intercambio"):

${ }^{63}$ Las utilidades generales producidas por la tierra son transformadas en utilidades específicas por el trabajo industrial. El elemento primitivo y concreto en tal dirección es el artesanal. FERGUSON, Un ensayo sobre la historia, cit., 225 y ss.

${ }^{64} \mathrm{Al}$ estamento burgués por excelencia no se le atestigua "sentido para la libertad y el orden", mientras que a los campesinos se les supone "tendencia al servilismo". FETSCHER; Actualidad y significado, cit., 35.

${ }^{65}$ En opinión de SOLARI, desde una consideración económica, son funcionarios improductivos, pero necesarios a los fines de la conservación social" (II concetto, cit.,238)

${ }^{66}$ Todo el desplazamiento económico y cultural que legitima el interés se refleja muy bien en HIRSCHMAN,A.,Las pasiones y los intereses. (Argumentos políticos a favor del capitalismo previos a su triunfo) .Barcelona, 1999.(Península). 
llena de equívocos: los dos conceptos expresan momentos diferenciados en la vida del espíritu. Tanto la persona como el miembro de la familia, como el ciudadano de la sociedad civil, son superados sin ser cancelados. En su obra clásica sobre el pensamiento político de HEGEL ${ }^{67}$, ROSENZWEIG había advertido sobre la escasa valoración del derecho y de la vida jurídica por parte del joven HEGEL. Paulatinamente, en su obra se va difuminando el dualismo entre el derecho abstracto y el derecho como una de las expresiones de la eticidad del Estado. Para que esta tendencia se afianzase y consumase, HEGEL necesitó estudiar a fondo el nuevo mundo económico así como elevar el concepto de sociedad civil a momento de la eticidad ${ }^{68}$. El concepto kantiano de la libertad externa ${ }^{69}$ sobre el que se funda el Estado de Derecho, le parece a HEGEL abstracto e inadecuado para las exigencias de la nueva civilización burguesa. Por esto, en su doctrina de la sociedad civil, se propone dar a la teoría del Estado de Derecho un contenido y un significado concretos; esto es, realidades éticas, no sólo jurídicas 0 morales ${ }^{70}$. Ética es también, la constitución que corresponde al "estado de necesidad"; ahora bien, como momento de la eticidad, la sociedad misma no puede ni debe estar aislada. Necesita una constitución. Ésta se explicita en una triple actividad: la teoría general de la ley(211); la referente a la administración de justicia(219) y el poder de policía.(230).

En esta constitución "social" hay una centralidad del derecho positivo y, en consecuencia, de la ley:"lo que es de derecho, al transformarse en ley, no sólo recibe la forma de su universalidad, sino su verdadera determinación. Debe existir un derecho públicamente conocido: "La obligatoriedad respecto de la ley encierra del lado del derecho de la autoconciencia(132)la necesidad de que las leyes sean hechas conocer universalmente"(215). El alcance de esta positividad tiene, sin embargo, su contrapunto:" lo que existe como ley puede diferir en su contenido de lo que es el derecho en sí"(212). Éste es el recordatorio de Hegel a los que olvidan que la realidad que persigue el sujeto es la razón, y aunque sólo tiene obligatoriedad como derecho lo que existe como ley(212), ésta puede, una y otra vez, sustraerse a las exigencias de la universalidad a la que el derecho, como idea de la libertad(1), está obligado. Es conocida la postura firme y fundamentada de HEGEL sobre la necesidad de un derecho codificado. Polemiza tanto contra el derecho inglés, no escrito, como contra la postura crítica de SAVIGNY contraria a la codificación ${ }^{71}$. Las posturas

\footnotetext{
67 ROSENZWEIG, F. “Hegel un der Staat”. (2 vols). Berlin,1962.(1ํed. Munich,1920). Para nuestro estudio, sobre todo, vol.II, págs. 118 y ss.; 186 y ss. Hay que reiterar la inexactitud de considerar que la vida política se agota en la concepción ética del Estado. El joven Hegel, había tenido muy presente la constitución platónica como expresión acabada de la justicia natural. Atravesando la juridicidad romana, con una personalidad subjetiva muy restringida, así como el agustinismo político, la eticidad natural del mundo agrícola hasta un Estado que reconoce y salvaguarda la personalidad jurídica y moral del ciudadano(como bourgeois) y como ciudadano del Estado. Sobre esta evolución, NEGRI; Stato e diritto nel giovane Hegel. (Studio sulla genesi illuministica della filosofia giuridica e politica di Hegel.). Padova1958. Pág.23: también, 85 y ss.

${ }^{68}$ ROSENZWEIG, "Hegel..", cit, vol.II, p.96. También, SOLARI, IL concetto, cit. 240.

${ }^{69}$ KANT,I."Principios metafísicos de la doctrina del derecho". Ed. de Arnaldo Córdova. México,1968. págs.132 y ss9

70 SOLARI, II concetto, cit. ,244. Sobre esta eticidad, reiterar, parágrafo 33, in fine.

${ }^{71}$ FETSCHER; Actualidad y significado, cit. 36.
} 
de ambos autores germinan y se desarrollan entre 1.802 y $1820^{72}$. El modelo de SAVIGNY se va a convertir en referencia dominante y en el núcleo de una razón jurídica ya completamente burguesa, ligada a una política moderada cuando no claramente conservadora ${ }^{73}$. En aquella constitución social y frente al ineludible formalismo del derecho privado moderno ${ }^{74}$, el objetivo que HEGEL asigna al Estado y a su legislación ante el formalismo "abstracto del derecho privado" es el objetivo de la justicia que se expresa en las buenas leyes: "En la sociedad civil, la universalidad es sólo necesidad: en la realización de las necesidades, el derecho como tal es lo único firme. Pero este derecho, un círculo restringido, se refiere sólo a la protección de lo que tengo; para el derecho como tal, el bienestar es algo exterior. Lo universal pues, que en un primer momento es sólo derecho, debe extenderse a la totalidad del campo de la particularidad. La justicia es algo muy importante en la sociedad civil: buenas leyes hacen florecer al Estado y una propiedad libre es la condición básica para su esplendor. Pero puesto que estoy totalmente enredado en la particularidad, tengo que reclamar el derecho de que en ese contexto también sea favorecido mi bienestar"(229;Agregado). Aquí realiza Hegel el "tránsito" desde la administración de justicia;-derecho positivo, ley, tribunales y procedimientos-, hacia el poder de policía," Se debe tender a mi bienestar, a $\operatorname{mi}_{75}$ particularidad, lo cual ocurre por medio de la policía y la corporación."

Por "policía"(POLIZEI), entiende HEGEL un conjunto de disposiciones administrativas, que forman un poder asegurador de lo universal(231). Más allá de los equívocos que suscita el término ${ }^{76}$,-utilizado con la significación propia de la administración del XVIII-, se refuerza el vínculo entre particularidad y universalidad, extendiéndolo desde la represión de la lesión del derecho en un caso singular, ( en base a la ley), a la prevención de la violaciones mediante la garantía de una seguridad ininterrumpida del singular en aquellos mismos bienes que eran protegidos por la administración de la justicia, a saber, libertad y propiedad $^{77}$.(230). El poder de policía es consecuencia de la insuficiencia de

72 En 1814, en Heidelberg, aparece "Vom Beruf unserer Zeit für Gesetzgebung und Rechtswissenschaft", mientras que en 1821 aparecerán en Berlin, los "Grundlinien" de nuestro autor. Para captar todas las singularidades del periodo que trascurre entre 1800 y 1821 , un texto importante es el de A. NEGRI, Alle origini del formalismo giuridico, Padova,1962.Págs.114 y ss.,

73 SCHIAVONE,A, "Los orígenes del derecho burgués", cit.22,23

74 SCHIAVONE,A., "Los orígenes", cit.82,83.

75 229; Agregado.

76 El traductor de nuestra edición de referencia, Juan Luis VERMAL, escribe, "Polizei" está usado en su acepción primera y más amplia de organización y reglamentación interna de un Estado. Para remarcar este sentido se utiliza "Poder de policía". "Principios", cit, 233, nota n56. Por su parte, José M $M^{a}$ RIPALDA escribe, "En países como España, "orden público" suena aún directamente a dictadura(así, "Tribunal de Orden Público") o, por lo menos, a "fuerzas del orden". En Derecho, en cambio, "orden público" significa el conjunto de ordenanzas que regulan en general la vida privada(..)El sentido originario de "policía" se ha desdibujado hoy demasiado como para que esté justificada la anacrónica traducción, incomprensiblemente habitual, de "Polizei" por "policía". OME,V, cit. 51.Según RIEDEL, cit,216, el concepto tal como se utiliza en los "Grundlinien" tiene muy poco que ver con el nuestro. Es un término que aparece con la institucionalización y burocratización del Estado moderno de los siglos XVII y XVIII y abarca la administración del Estado de una sociedad que se ha vuelto diferenciada.

217; Agregado.218. Vid. Asimismo, Giuliano MARINI; Estructura y significados de la sociedad civil hegeliana. En Los "Estudios sobre la Filosofía del derecho de Hegel”, cit, 234. 
la actividad meramente jurídica". A estas alturas del discurso hegeliano, se puede hablar de multitud de "disposiciones" y elementos con vigencia contemporánea ${ }^{78}$. En cualquier caso, toda la exposición hegeliana nos sugiere una correlación paradójica entre una deficiencia de lo jurídico y una abundancia de lo político ${ }^{79}$. HEGEL no limitó el objetivo del "estado de necesidad" a la defensa, y reconocimiento de la personalidad en el accidentado territorio de la vida económica. Estos derechos, como es sabido, eran referencias muy claras en LOCKE y en KANT. Todas las cautelas eran pocas a la hora de evitar interferencias del Estado en la actividad del sujeto social. De forma bien distinta, HEGEL dota a la forma social de unas instancias relevantes,-policía y corporación-, que traten de neutralizar los efectos negativos del marco económico de referencia:"las acciones privadas se convierten en una contingencia que escapa a mi poder y pueden ocasionar y ocasionan daños o injusticias a otros"(232). Es importante no olvidar que el carácter" natural" o "imperioso" de las necesidades humanas se cultiva y desarrolla en un medio social egoísta y arbitrario. No por ello ha de perderse el espíritu ético; éste reaparece en la constitución de un sistema en el que la cooperación recíproca, esté debidamente regulada, ya que "los diversos intereses de productores y consumidores pueden entrar en un conflicto entre sí y si bien en el todo, la relación correcta se produce por sí misma ${ }^{80}$, la compensación requiere una regulación consciente que esté por encima de ambas partes"(236). Entre el orden económico y el orden jurídico, entre el reino del instinto y el de la razón existe un desequilibrio ${ }^{81}$, una falta tan acusada que en la sociedad civil no puede resolverse. Vano es esperar que tal sociedad produzca un acuerdo entre la subjetividad y la idea objetiva que esa misma sociedad viene a expresar ${ }^{82}$. Precisamente es la importancia que HEGEL concede a determinados mecanismos de control y prevención la que caracteriza e intensifica las diferencias con la filosofía económica liberal. El "espíritu ético",-la unión entre lo particular y lo universal-, se extravía cuando la producción de una ingente riqueza está asociada necesariamente a la pobreza y el desarraigo: "Al igual que el arbitrio, también otras circunstancias casuales,

\footnotetext{
${ }^{78}$ FETSCHER, Actualidad y significado, cit., 36

${ }^{79}$ 230;232. SOLARI; II concetto, cit.,246,247.

80 Observemos que continuamente aparece el "ritornello" característico de la obra de Adam SMITH, muy bien conocida por HEGEL. Hay una universalidad que domina las particularidades aparentemente dispersas( (la "mano invisible"). Cada uno cree trabajar para sí en la búsqueda de los medios que le proporcionen subsistencia y bienestar y, sin embargo, está dirigido por una racionalidad universal, la cual hace que trabaje también para los demás, según un designio universal de la razón. Vid. MARINI, cit.232.

${ }^{81}$ Signo de los tiempos y de los cambios de la forma social. La racionalización del mercado y del capital avanzarán con tal intensidad a lo largo del XIX, que un ilustre epígono de los neokantianos, Max WEBER, observará el orden económico y el orden jurídico como dos instancias completamente imbricadas; dos expresiones de la materia social que sustenta la validez empírica. ¿Ha desaparecido el reino de la razón?."Si el orden económico y el jurídico se encuentran mutuamente en la más íntima relación, ello significa que éste último no se entiende en sentido jurídico sino sociológico: como validez empírica. En este caso, el sentido de la expresión "orden jurídico" cambia totalmente. Entonces no significa un cosmos lógico de normas correctamente inferidas, sino un complejo de motivaciones del actuar humano real". Vid. WEBER, Economia y Sociedad.(México,1964/4ªed./FCE), Vol.I, 251,252..

${ }^{82}$ SOLARI, II concetto, cit,247. Para todas las referencias a la intervención de los mecanismos económicos así como las reflexiones de HEGEL inspiradas por los efectos "miserabilizadores" de las transformaciones económicas se pueden consultar las páginas 118 y ss. de ROSENZWEIG, Hegel un der Staat, cit.
} 
físicas o que dependen de condiciones exteriores(240), pueden reducir a los individuos a la pobreza"(241). Además de la ayuda moral, del sentimiento y del amor que aspiran a mitigar lo subjetivo de la pobreza(242), cuando nos enfrentamos a "la caída de una gran masa por debajo de un cierto nivel mínimo de subsistencia, que se regula por sí solo como el nivel necesario para un miembro de la sociedad, y la pérdida consiguiente del sentimiento del derecho, de lo jurídico y del honor de existir por su propia actividad y trabajo, lleva al surgimiento de una plebe que por su parte proporciona la mayor facilidad para que se concentren en pocas manos riquezas desproporcionadas."(244) Entonces, hay que pensar en el específico y real ámbito de la eticidad: poder de policía, orden exterior, instituciones para la seguridad y la protección del conjunto fines e intereses particulares: "puesto que, de acuerdo con la idea, la particularidad misma toma a este universal que está en su interés inmanente como fin y objeto de su voluntad y actividad, lo ético vuelve como algo inmanente a la sociedad civil. Esta es la función de la corporación"(249).

El concepto de Corporación (Korporation), una mediación muy singular y característica, va a constituir una fuente de equivocidad y también de críticas en lo que se refiere a la estructura de su relación con el Estado contemporáneo. Por lo demás, asombra su ubicación en el seno de la clase industrial ${ }^{83}$. HEGEL busca aquí un elemento común que le permita reconstruir, una vez más, la eticidad perdida. Intentado hacer de un "fin egoísta", un fin universal ${ }^{84}$; totalmente concreto(251). La nueva configuración que la sociedad civil está adquiriendo en clases sociales delimitadas por la forma de la producción, determina que la familia,-antaño núcleo de la vida económica-, pierda la importante función que jugaba ${ }^{85}$. En consecuencia, se piensa en la necesidad de contar con un supuesto asociativo que venga a suplir aquella civilidad característica de la familia. El conjunto de los trabajadores industriales, que HEGEL delimita de forma muy sincrética, debe buscar protección no tanto en la instancia estatal cuanto en los esfuerzos asociativos propios(255;Agregado).En absoluto se trata de resucitar las viejas corporaciones medievales: "en y por sí, la corporación no es un gremio cerrado, sino el devenir ético de las profesiones individuales y su elevación a un círculo en el que adquieren fuerza y honor(255;Agregado). Esta corporación tiene, bajo el control del poder público, el derecho de cuidar de sus propios intereses(252), y para sus miembros, adquiere el lugar de una segunda familia. ${ }^{86}$ Como miembro de la asociación posee un privilegio,-no como excepción de la ley general-, sino como cualidad de pertenencia a una rama

\footnotetext{
83 "La clase agrícola tiene su universal concreto, en el que vive, inmediatamente en sí misma, en la sustancialidad de su vida familiar y natural. La clase universal tiene en su determinación lo universal como su terreno y como el fin de su actividad. El medio entre ambas, la clase industrial, está dirigida esencialmente a lo particular y por eso le corresponde de un modo propio la corporación".(250)

${ }^{84}$ VOGEL; Hegel Gesellschaftsbegriff, cit, 63 y ss; sobre todo, ROSENZWEIG, Hegel und der Staat, cit., 186 y ss. SOLARI, II concetto, cit., 251.

${ }^{85}$ En el 255, leemos, "Después de la familia, la corporación constituye la segunda raíz ética del Estado, hundida en la sociedad civil..."

86 "En la corporación la ayuda que recibe la pobreza, pierde su carácter accidental y lo que hay en ella de injustamente humillante. Al mismo tiempo la riqueza, al cumplir sus deberes con la corporación, deja de provocar el orgullo de su poseedor y la envidia de los demás. De este modo la honestidad recibe su verdadera honra y reconocimiento"(253; Obs).
} 
esencial de la sociedad que tiene muy presente un fin común y general. HEGEL se rebela contra la opinión liberal que observa a la corporación como limitadora de la libre iniciativa económica: "En la corporación el llamado derecho natural de utilizar sus habilidades y ganar con ellas todo lo posible sólo se limita en la medida en que se las destina de un modo racional, es decir se las libera de la accidentalidad y de la opinión personal, que pueden ser peligrosas para sí mismo y para los demás, y de este modo se las reconoce, se las asegura y se eleva al mismo tiempo al nivel de una actividad consciente para un fin común"(254)

En las interpretaciones más conocidas de la Filosofía del derecho de HEGEL, es frecuente hallar criterios muy reductivos de sus densas reflexiones sobre la sociedad civil. En general, hay una distinción insuficiente entre el sistema de las necesidades, el momento económico, y la complejidad de la sociedad civil en general como momento relativo de la eticidad. Sin embargo, no podemos subestimar la precisión y riqueza con la que HEGEL delimita el concepto de sociedad civil como forma diferenciada del Estado; como sociedad "no política" - "Estado externo". Sociedad civil que se distancia de cualquier supuesto naturalista prepolítico ${ }^{87}$, habida cuenta de la distancia crítica de este autor respecto de los esquemas aprioristas del contractualismo. HEGEL consigue una visión clara de la sociedad civil moderna. En plena vigencia del liberalismo doctrinario, exaltador de una forma social de agregación de hombres libres y propietarios, refractarios a cualquier ingrediente que pudiera menoscabar el "individualismo soberano", se incorpora una forma social, transitiva y compleja, que incorpora el derecho abstracto y lo subsume en una eticidad compleja y dinámica. Una nueva forma de civilidad que exalta al hombre socializado como ciudadano, en la dialéctica irreversible que discurre del "yo" al "nosotros". HEGEL tiene muy presente al ROUSSEAU del "Discurso" que presenta un sentido vivo de la vida social como sistema de necesidades y voluntades particulares ${ }^{88}$, pero no comparte la idea del "Contrato", fruto de una supuesta voluntad agregada, que subyace a la formación de un Estado con una eticidad impedida, ya que no deja subsistir junto a sí ninguna sociedad particular ${ }^{89}$ Sobre estos supuestos precisos, KANT concibió un Estado "a priori" como sociedad organizada en "la dependencia legal' y en "la voluntad legislativa propia" que garanticen la libertad de los ciudadanos ${ }^{90}$. Es HEGEL, sin embargo el que concibe una sociedad civil como momento del desdoblamiento, entre la decisión del arbitrio subjetivo y la libertad objetiva; y como momento de tránsito y unificación hacia la libertad concreta en la que la individualidad personal y sus intereses particulares tengan su total desarrollo y el reconocimiento de su derecho, al mismo tiempo que se convierten por sí mismo en interés general ${ }^{91}$. Esta idea, está ya plenamente incorporada a nuestra conciencia histórica.

\footnotetext{
${ }^{87}$ DE GIOVANNI,B, Hegel e il tempo storico della societá borguese, cit, 183 y ss.. MARINI, G., Estructura y significado, cit,244.

${ }^{88}$ ROUSSEAU, Discurso sobre el origen de la desigualdad entre los hombres. Madrid,1972/110

${ }^{89}$ ROUSSEAU, El Contrato social, Madrid,1969. pág.34

${ }^{90}$ KANT, Principios Metafísicos, cit. 145.

${ }^{91}$ HEGEL; Grundlinien, 260.
} 